\title{
Do educational materials change knowledge and behaviour about crying and shaken baby syndrome? A randomized controlled trial
}

\author{
Ronald G. Barr MDCM, Marilyn Barr BIS, Takeo Fujiwara MD PhD, Jocelyn Conway BA, \\ Nicole Catherine MSc, Rollin Brant PhD
}

Published at www.cmaj.ca on Mar. 2, 2009.

$\infty$ See related commentary by Jenny, page 703

\section{ABSTRACT}

Background: Shaken baby syndrome often occurs after shaking in response to crying bouts. We questioned whether the use of the educational materials from the Period of PURPLE Crying program would change maternal knowledge and behaviour related to shaking.

Methods: We performed a randomized controlled trial in which 1279 mothers received materials from the Period of PURPLE Crying program or control materials during a home visit by a nurse by 2 weeks after the birth of their child. At 5 weeks, the mothers completed a diary to record their behaviour and their infants' behaviour. Two months after giving birth, the mothers completed a telephone survey to assess their knowledge and behaviour.

Results: The mean score (range 0-100 points) for knowledge about infant crying was greater among mothers who received the PURPLE materials (63.8 points) than among mothers who received the control materials (58.4 points) (difference 5.4 points, $95 \%$ confidence interval $[\mathrm{Cl}] 4.1$ to 6.5 points). The mean scores were similar for both groups for shaking knowledge and reported maternal responses to crying, inconsolable crying and self-talk responses. Compared with mothers who received control materials, mothers who received the PURPLE materials reported sharing information about walking away if frustrated more often $(51.5 \%$ v. $38.5 \%$, difference $13.0 \%$, $95 \% \mathrm{Cl} 6.9 \%$ to $19.2 \%)$, the dangers of shaking ( $49.3 \% \mathrm{v}$. $36.4 \%$, difference $12.9 \%, 95 \% \mathrm{Cl} 6.8 \%$ to $19.0 \%$ ), and infant crying $(67.6 \%$ v. $60.0 \%$, difference $7.6 \%, 95 \% \mathrm{Cl} 1.7 \%$ to $13.5 \%)$. Walking away during inconsolable crying was significantly higher among mothers who received the PURPLE materials than among those who received control materials $(0.067$ v. 0.039 events per day, rate ratio $1.7,95 \% \mathrm{Cl} 1.1$ to 2.6 ).

Interpretation: The receipt of the Period of PURPLE Crying materials led to higher maternal scores for knowledge about infant crying and for some behaviours considered to be important for the prevention of shaking. (ClinicalTrials.gov trial register no. NCT00175422.)

Une version française de ce résumé est disponible à l'adresse www.cmaj.ca/cgi/content/full/180/7/727/DC1

CMAJ 2009;180(7):727-33

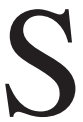
haken baby syndrome, or inflicted traumatic brain injury, is caused by the violent shaking of a child with or without contact between the child's head and a hard surface. Such contact may result in head trauma, including subdural hematoma, diffuse axonal injury and retinal hemorrhage. The annual estimated rate of inflicted traumatic brain injury is 30 cases per 100000 children aged 1 year of younger. ${ }^{1,2}$ Because shaken baby syndrome is inflicted by a care giver and because of a lack of awareness about the damage caused by shaking, shaken baby syndrome may be preventable. There are no randomized controlled trials of materials to prevent shaken baby syndrome. ${ }^{3}$ Information provided to new parents at birth about the dangers of shaking their child may decrease the incidence of shaken baby syndrome. ${ }^{4}$

Crying is a common stimulus for shaking. ${ }^{3-9}$ The agespecific incidence curves for shaken baby syndrome have similar onsets, shapes and peak patterns as for crying in healthy infants..$^{5-7}$ Crying increases in the first month after birth, peaks in the second month, and decreases by the fourth month. ${ }^{8-10}$ Prolonged, inconsolable and unpredictable episodes of crying that cluster in the evening occur only during the first few months after birth. These episodes are a source of frustration and anger for parents. ${ }^{11,12}$ Policy statements recommend that anticipatory guidance about crying be given to parents to help prevent shaken baby syndrome. ${ }^{13,14}$

The Period of PURPLE Crying program materials ${ }^{15}$ use the association between crying and shaken baby syndrome to educate parents about the dangers of shaking and the importance of sharing this information with other caregivers. Because shaken baby syndrome can occur by week 2, , $^{1,5}$, information should be given to parents before or soon after birth.

The aim of our study was to investigate the effect of providing mothers with the Period of PURPLE Crying materials on their knowledge and behaviour related to the prevention of shaken baby syndrome.

From the Centre for Community Child Health Research (R. Barr, Fujiwara Catherine), Child and Family Research Institute, University of British Columbia; the Departments of Pediatrics (R. Barr, Fujiwara) and Statistics (Brant), University of British Columbia; Prevent Shaken Baby Syndrome BC (M. Barr, Conway), BC Children's Hospital, Vancouver, BC; and the National Center on Shaken Baby Syndrome (M. Barr), Ogden, USA 


\section{Methods}

\section{Study population and design}

Participants were recruited from hospitals in the Greater Vancouver Area, British Columbia, between May 2005 and November 2006. We included mothers who had an uneventful pregnancy, a healthy singleton infant (> 37 weeks' gestation), access to a DVD player and who were fluent in English. Research assistants or discharge nurses recruited mothers at 6 hospitals by obtaining consent for initial contact. After obtaining verbal consent to participate either in person or by telephone, participants were randomly assigned to receive the Period of PURPLE Crying materials (an 11-page booklet and a DVD) or the control injury prevention materials ( 2 brochures and a DVD about infant safety) during routine visits with a public health nurse within 2 weeks after discharge. The package included a Baby's Day Diary ${ }^{16}$ with instructions, a sealed envelope with the study materials, and a teddy bear. Nurses demonstrated how to use the diary during the visit. The nurses were blinded as to whether the mothers received the PURPLE materials or the injury prevention materials.

Five weeks after giving birth, the participating mothers were contacted by telephone 1 day before and 1 day after starting to use the diary to facilitate completion of the diary. At 8 weeks, the mothers were telephoned by an independent research group whose staff were blinded to the study hypotheses, materials and groups. The mothers completed a questionnaire, which took about 20 minutes. Participants received a certificate of appreciation and a $\$ 25$ cheque.

The questionnaire included questions about the mother's knowledge about crying and shaking, behaviour in the past month in response to crying and inconsolable crying, the number and relationships of caregivers other than mother, and whether information was shared with each caregiver. Because there were no previously established relevant measures of crying, shaking or safety knowledge and behaviours, all questions were created for this study. Outcome measures were defined during data collection and prior to analysis.

Ethics approval was granted by the behavioural ethics review board of the University of British Columbia.

\section{Study materials}

The PURPLE materials were developed by the National Center on Shaken Baby Syndrome. ${ }^{15}$ The letters in PURPLE each stand for a property of crying in healthy infants that frustrates caregivers ( $\mathrm{P}$ for peak pattern, in which crying increases, peaks during the second month and then declines; $U$ for unexpected timing of prolonged crying bouts; $\mathrm{R}$ for resistance to soothing; P for pain-like look on the child's face; L for long crying bouts; and $\mathrm{E}$ for late afternoon and evening clustering). The PURPLE materials reinforce that these are normal properties, suggest ways to soothe, underline that soothing is not always expected to work, describe why inconsolable crying is frustrating to parents, and suggest 3 guidelines when caring for a crying infant. First, parents are encouraged to use typical calming responses (carry, comfort, walk and talk) with their infants. Second, if the crying is too frustrating, it is okay put the baby down in a safe place, walk away, calm yourself and then return to check on the baby. Third, never shake a baby.

The PURPLE materials describe shaken baby syndrome, and emphasize telling other caregivers about the "period of PURPLE crying," the frustration of caring for a crying child, the dangers of shaking, and the recommended responses to the baby's crying. The materials do not claim that inconsolable crying is consolable if caregivers act appropriately; ${ }^{9-11,17}$ rather, the program acknowledges the frustration that occurs when an infant is inconsolable.

Mothers in the control group received the Canadian Pediatric Society's brochure Safety Tips for Parents, Health Canada's brochure on sleep position and sudden infant death syndrome and a DVD of clips from the Back to Sleep campaign (National Institute of Child Health and Human Development) and the Safe Start program at BC Children's Hospital on infant safety. ${ }^{18-21}$

\section{Outcomes}

We included 8 primary outcome measures. Of these, 5 were scales that measured crying knowledge, shaking knowledge, general responses to crying, responses to inconsolable crying, and self-talk responses to inconsolable crying (Appendix 1, available at www.cmaj.ca/cgi/content/full/cmaj.081419 /DC1). We transformed the scales to the range of 0-100 points; higher scores indicated better knowledge or improved behaviours. Three outcomes measured information-sharing behaviours, defined as the percentage of mothers who shared information with at least 1 caregiver for each of 3 topics: crying, walking away if frustrated, and the danger of shaking.

Four secondary outcomes were derived from the mothers' entries in the Baby's Day Diary ${ }^{16}$ of the behaviours of the infant (including fussing, crying, inconsolable crying) and caregiver (body contact). These outcomes have been previously described, used widely and tested for reliability and validity. 12,22-27 "Distress" included fussing, crying or inconsolable crying. ${ }^{28}$ As in other studies, ${ }^{29,30}$ parents indicated prespecified events (picking up the crying infant; putting the infant down, walking away and taking a break), which are actions recommended in the PURPLE materials. Diaries were transcribed into a counting program $\left(\operatorname{RonNicLog}{ }^{28}\right)$. Mean interrater reliability scores (kappa) ${ }^{31}$ from a $7 \%$ sample were 0.99 for behaviours and 0.75 for events. The 3 outcomes derived from the diaries were caregiver contact when infant was distressed (minutes per day), pick-up events when infant was distressed (events per day), and walk-away events when infant cried inconsolably (events per day). The fourth outcome was a 6-point Likert scale of frustration in response to the question "How frustrating to you was your baby's crying today?"

\section{Statistical analyses}

For several outcomes, we determined that 1052-4058 participants were required to achieve $90 \%$ power to detect a mean difference of $10 \%$ between participants in the intervention and control groups, using $\alpha=0.05$ for a 2 -sided test with equal numbers in each group. We sought to enroll about 1200 mothers. 
For primary analyses, we used known data. However, we also performed parallel sensitivity analyses using multiple imputation based on the method of chained equations (regression switching), randomly sampling the imputed values from the posterior predictive distribution of the missing data. ${ }^{32-34}$ Unless noted, the results of analyses using multiple imputation methods were essentially the same as the results obtained using known data.

The analytic strategy was determined independently of any results from the study. For continuous measures, the mean difference between participants in the PURPLE group and the control was estimated by use of a $t$ test. For diary event counts, we estimated the incidence rate ratios (RR) using negative binomial regression. ${ }^{35,36} \mathrm{We}$ used tests of statistical inter- action to examine subgroups based on education, whether the intervention was read or viewed, parity (1st child v. $>1$ st child), and whether the infant had inconsolable crying. Main effect terms were included for tests of interaction. ${ }^{37}$ If measures were not normally distributed, we confirmed significance using a nonparametric comparison.

\section{Results}

We approached 3240 mothers (Figure 1), and 2331 mothers were invited to participate. Of these, 1833 mothers in 4 health regions consented to participate and were randomly assigned to permuted blocks of 2 or 4 . Because our aim was to test the materials and not the delivery of the materials, we excluded

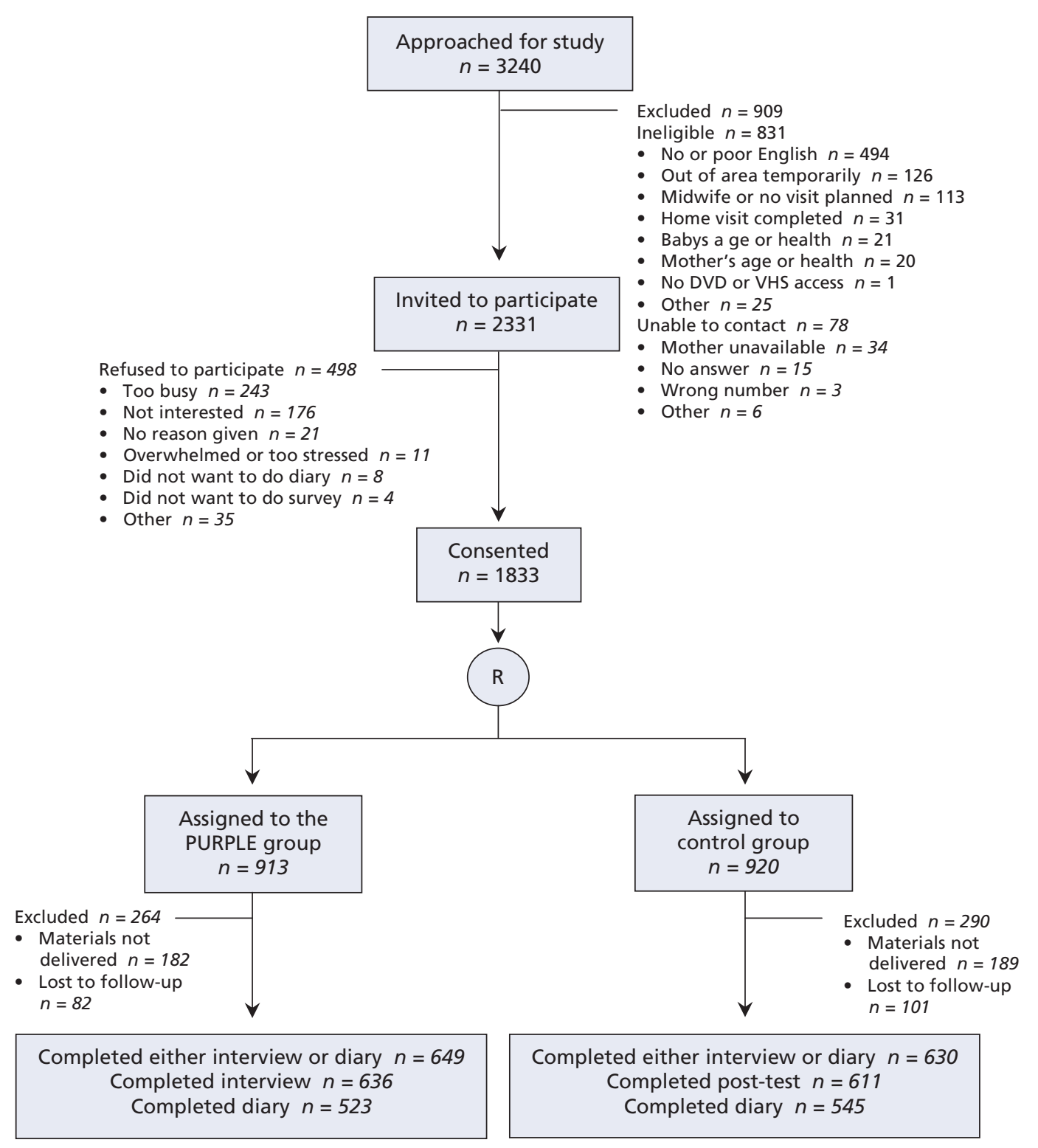

Figure 1: Selection of participants for inclusion in the randomized controlled trial of the effect of educational materials on maternal knowledge and behaviour about shaken baby syndrome. Note: $\mathrm{R}=$ randomization. 
participants who did not receive a visit from a nurse or who were lost to follow-up. The final intention-to-treat analysis included 649 mothers who received the PURPLE materials and 630 mothers who received the control materials who com-

Table 1: Characteristics of the mothers included in the study of the prevention of shaken baby syndrome by the provision of educational materials to mothers

\begin{tabular}{|c|c|c|}
\hline \multirow[b]{2}{*}{ Characteristics } & \multicolumn{2}{|c|}{ Group; no. (\%) of participants } \\
\hline & $\begin{array}{c}\text { PURPLE* } \\
n=649\end{array}$ & $\begin{array}{c}\text { Controlt } \\
n=630\end{array}$ \\
\hline \multicolumn{3}{|l|}{ Demographic } \\
\hline \multicolumn{3}{|l|}{ Mothers' age, yr } \\
\hline$<25$ & $65(10)$ & $40 \quad(7)$ \\
\hline $25-30$ & $150(24)$ & $141(23)$ \\
\hline $30-35$ & $221(35)$ & $248(41)$ \\
\hline$>35$ & $192(31)$ & $182(30)$ \\
\hline \multicolumn{3}{|l|}{ Education (yr) } \\
\hline High school or less $(\leq 12)$ & 91 (14) & $79(13)$ \\
\hline In college (13-15) & 208 (33) & $173(28)$ \\
\hline Completed college (16) & $142(22)$ & $150(25)$ \\
\hline Graduate studies ( $\geq 17$ ) & $194(31)$ & $208(34)$ \\
\hline \multicolumn{3}{|l|}{ Annual household income, \$ } \\
\hline$<40000$ & $125(22)$ & $147(25)$ \\
\hline $40000-100000$ & $299(52)$ & $298(51)$ \\
\hline$>100000$ & $146(26)$ & $144(24)$ \\
\hline \multicolumn{3}{|l|}{ Marital status } \\
\hline Married & $506(83)$ & $514(81)$ \\
\hline Living with partner & $69(11)$ & $72(11)$ \\
\hline Never married & $35 \quad(6)$ & $49 \quad(8)$ \\
\hline \multicolumn{3}{|l|}{ Parity } \\
\hline First baby & $365(58)$ & $361(59)$ \\
\hline \multicolumn{3}{|l|}{ Recruitment or material } \\
\hline \multicolumn{3}{|l|}{ Region } \\
\hline Vancouver & 243 (37) & $241(38)$ \\
\hline Fraser South & $191(29)$ & $182(29)$ \\
\hline Fraser North & $176(27)$ & $170(27)$ \\
\hline North Shore & $39 \quad(6)$ & $37 \quad(6)$ \\
\hline \multicolumn{3}{|l|}{ Material delivered by } \\
\hline Public health nurse & 576 (89) & $573(91)$ \\
\hline Research assistant & $63(10)$ & $43 \quad(7)$ \\
\hline No delivery & $10 \quad(2)$ & $14 \quad(2)$ \\
\hline \multicolumn{3}{|l|}{ Exposure to materials } \\
\hline Neither & $23 \quad(4)$ & $24 \quad(4)$ \\
\hline Watched video only & $30 \quad(5)$ & $46 \quad(8)$ \\
\hline Read pamphlet only & 89 (15) & $81(14)$ \\
\hline Both & $472(77)$ & $430(74)$ \\
\hline
\end{tabular}

* Mothers in the PURPLE group received an 11-page booklet and a DVD from the Period of PURPLE Crying Program. ${ }^{15}$

tMothers in the control group received 2 brochures and a DVD about infant safety. ${ }^{1821}$ pleted the interview, diary, or both. The baseline characteristics of mothers in both groups were similar, which suggests that there was no selection bias (Table 1).

Of the 1279 participants, data about age were missing for $3 \%$, education for $3 \%$, family income for $9 \%$ and marital status for 3\%. Data for all 5 knowledge and behaviour scales were missing for $4 \%$ of women. Compared with women who responded to at least 1 primary outcome scale, women missing data for all 5 primary outcome scales had less education (completed high school, $24 \%$ v. 14\%), lower incomes $(<\$ 40000,74 \%$ v. $23 \%)$ and were less often in the intervention arm (40\% v 51\%). Age and marital status were similar among women with data for at least 1 outcome and those missing data for 5 outcomes. All 4 of the diary measures were missing for $17 \%$ of the participants.

Scores on the scale that measured crying knowledge were higher among mothers who received the PURPLE materials (63.8 points) than among mothers who received the control materials (58.4 points, difference 5.4 points, $95 \%$ CI 4.1 to 6.5 points, $p<0.001)$. The difference in the scores for shaking knowledge were not statistically significant between the 2 groups ( 84.0 points v. 83.2 points, difference 0.8 points, $95 \%$ CI -0.4 to 1.9 points, $p=0.20$ ).

Compared with the scores among mothers who received control materials, the scores were higher among mothers who received the PURPLE materials for response to crying (48.3 points v. 48.2 points, difference 0.1 points, $95 \%$ CI -1.5 to 1.7 points, $p=0.90)$, response to inconsolable crying (27.7 points v. 26.0 points, difference 1.7 points, $95 \% \mathrm{CI}-0.6$ to 4.1 points, $p=0.15$ ), and self-talk response ( 36.0 points $\mathrm{v}$. 32.9 points, difference 3.1 points, $95 \% \mathrm{CI}-0.3$ to 6.4 , $p=0.08)$. These differences were not statistically significant.

More mothers in the PURPLE group than in the control group shared information with other caregivers about walking away if frustrated by inconsolable crying $(51.5 \%$ v. $38.5 \%$, difference $13.0 \%, 95 \%$ CI $6.9 \%$ to $19.2 \%, p<0.001$ ), the danger of shaking $(49.3 \%$ v. $36.4 \%$, difference $12.9 \%, 95 \%$ CI $6.8 \%$ to $19.0 \%, p<0.001)$, and crying $(67.6 \%$ v. $60.0 \%$, difference $7.6 \%, 95 \%$ CI $1.7 \%$ to $13.5 \%, p=0.01$ ).

When we performed the analysis using only known data, mothers who received the PURPLE materials were more likely than mothers who received the control materials to walk away when their infant cried inconsolably ( 0.067 times per day v. 0.039 times per day, RR $1.7,95 \%$ CI 1.1 to 2.6, $p=0.01$ ). When we performed the analysis using multiply imputed data, walking away occurred 1.5 times more frequently among mothers in the PURPLE group than among mothers in the control group (0.066 times per day v. 0.044 times per day, RR $1.5,95 \%$ CI 1.0 to $2.2, p=0.05$ ).

There was no significant difference in the frequency of picking up the infants between mothers in the PURPLE group (3.57 times per day) and mothers in the control group (3.61 times per day, RR $0.99,95 \% \mathrm{CI}-0.9$ to $1.1, p=0.83$ ). There was no difference in the length of time of contact when the infant was distressed among mothers in the PURPLE group (109.8 minutes per day) and those in the control group (106.1 minutes per day; difference 3.7 minutes per day, 95\% CI -4.2 to $11.6, p=0.36$ ). The level of frustration was not statis- 
tically different between mothers in the PURPLE group (1.19) and those in the control group (1.25) (difference -0.06, $95 \% \mathrm{CI}-0.18$ to $0.05, p=0.26$ ). The duration and frequency of distress, fussing, crying and inconsolable crying were not statistically different between the groups (all $p>0.1$ ).

The effect of receiving the PURPLE materials on maternal knowledge about crying was greater among women who watched the DVD, read the materials, or both (Table 2). The effect of PURPLE materials on knowledge about shaking was greater among those with more education. There was little evidence that the effect of the PURPLE materials varied on any other scale by education level, reading or viewing the materials, being the mother's first baby, or inconsolable crying.

\section{Interpretation}

We found that mothers who received the PURPLE materials scored 5\% higher than mothers who received the control materials on the scales that measured knowledge about crying. Compared with mothers who received the control materials, mothers who received the PURPLE materials more often shared descriptions of crying ( $8 \%$ difference), advice about walking away if frustrated (13\% difference) and warnings about the danger of shaking (13\% difference). Small improvements on the behaviour scales for crying and inconsolable crying were not statistically significant. Walk-away behaviour when faced with inconsolable crying was 1.7 times more frequent among mothers who received the PURPLE materials than among those who received the control materi- als. Maternal contact, the number of pick-up events during distress and the daily levels of frustration were similar between the 2 groups. The difference in knowledge about crying varied depending on whether the mothers viewed or read, or both, the materials provided. This supports the interpretation that use of the materials resulted in the observed difference. There is no evidence that the education level of the mother (except for shaking knowledge), being the first baby, or inconsolable crying influenced the effect of the intervention. Thus, the PURPLE program may be effective in other populations unless they differ in terms of demographic characteristics not measured in this study.

Since the normality of frustrating properties of early increased crying is neither widely known nor accurately represented in parental advice literature, ${ }^{38}$ the significant increase in crying knowledge was important. As previously reported, ${ }^{39}$ mothers' awareness of the dangers of shaking was high in both groups, and we found no further gain after receipt of the PURPLE materials compared with the control materials. The change in knowledge about crying represented a Cohen's effect size ${ }^{40}$ of 0.46 , which was twice the average effect size of short-term (0.23) or long-term (0.27) effects of 108 interventions that measured changes in parenting knowledge and attitudes..$^{41}$ The gain in information-sharing behaviours about the normal properties of crying, walking away if frustrated, and the danger of shaking is important because, after the biological parents, temporary caregivers (especially men) are the most common perpetrators of shaking..$^{13,42-44}$ Mothers who received the PURPLE materials reported a higher rate of

Table 2: Subgroup analyses of maternal knowledge and behaviour related to shaken baby syndrome.

\begin{tabular}{|c|c|c|c|c|c|}
\hline Subgroup & \multicolumn{5}{|c|}{ Difference in mean scores (PURPLE group* scores - control group † scores) $(95 \% \mathrm{CI}) \ddagger$} \\
\hline Education & $p=0.23$ & $p=0.02$ & $p=0.56$ & $p=0.26$ & $p=0.14$ \\
\hline High school or less & $3.7(0.1$ to 7.4$)$ & $-2.4(-5.9$ to 1.2$)$ & $-0.2(-5.2$ to 4.8$)$ & $2.2(-4.2$ to 8.6$)$ & $-2.5(-12.1$ to 7.1$)$ \\
\hline Some college & 7.1 (4.8 to 9.4$)$ & $-0.1(-2.0$ to 1.9$)$ & $1.4(-1.5$ to 4.4$)$ & $4.5(0.5$ to 8.5$)$ & 7.9 (1.9 to 13.9$)$ \\
\hline $\begin{array}{l}\text { Materials read or } \\
\text { viewed }\end{array}$ & $p=0.02$ & $p=0.45$ & $p=0.35$ & $p=0.24$ & $p=0.84$ \\
\hline Neither & $-2.4(-10.4$ to 5.5$)$ & $-3.6(-9.7$ to 2.4$)$ & $-3.4(-11.7$ to 4.9$)$ & $-10.6(-24.1$ to 3.0$)$ & $-2.6(-20.5$ to 15.3$)$ \\
\hline Watched DVD & $1.8(-3.6$ to 7.2$)$ & $0.5(-5.3$ to 6.3$)$ & 1.5 (-4.9 to 7.9$)$ & $1.3(-8.1$ to 10.7$)$ & $-0.5(-14.3$ to 13.3$)$ \\
\hline Read pamphlet & $3.6(0.1$ to 7.1$)$ & $-0.2(-3.4$ to 3.0$)$ & $-2.8(-7.4$ to 1.8$)$ & 2.6 (-3.9 to 9.0$)$ & $1.6(-7.6$ to 10.9$)$ \\
\hline Yes & 5.1 (3.4 to 6.8 ) & $0.5(-1.0$ to 2.0$)$ & $-0.1(-2.1$ to 2.0$)$ & $2.8(-0.3$ to 5.8$)$ & 5.2 (0.8 to 9.6$)$ \\
\hline $\begin{array}{l}\text { Infant had } \\
\text { inconsolable crying }\end{array}$ & $p=0.34$ & $p=0.12$ & $p=0.47$ & $p=0.32$ & $p=0.57$ \\
\hline No & 5.2 (3.3 to 7.1$)$ & 1.8 (0.2 to 3.3$)$ & $0.0(-2.3$ to 2.3$)$ & $0.3(-3.0$ to 3.6$)$ & $1.4(-3.2$ to 6.1$)$ \\
\hline Yes & 6.5 (4.5 to 8.6 ) & $-0.1(-2.0$ to 1.7$)$ & $1.3(-1.2$ to 3.7$)$ & $2.8(-0.9$ to 6.5$)$ & 3.5 (-1.9 to 8.9$)$ \\
\hline
\end{tabular}

Note: $\mathrm{Cl}=$ confidence interval.

* Mothers in the PURPLE group received an 11-page booklet and a DVD from the Period of PURPLE Crying Program. ${ }^{15}$

tMothers in the control group received 2 brochures and a DVD about infant safety. ${ }^{18-21}$

$\ddagger p$ values are for the difference estimates across subgroups. 
walking away with inconsolable crying, as recommended by the PURPLE program.

This assessment was designed as a conservative test of the effect of the PURPLE materials. The study nurses did not know which materials they were delivering. The intervention may have had stronger effects if the nurses had reinforced the messages, ${ }^{4}$ or if the messages were reinforced by multiple exposures through prenatal, maternity and postnatal health care providers, media and community support organizations. In the successful Back to Sleep campaign, the impact of the campaign on behaviour change was because of the combined effects of advice given by clinicians and nurses, reading materials, and print and broadcast media. ${ }^{45}$

A similar randomized controlled trial of the PURPLE materials has been performed in Seattle, United States. ${ }^{32}$ The materials were delivered to mothers in prenatal classes, maternity wards and pediatric offices by research assistants (not health care professionals). There was a 6.2 point increase in crying knowledge, a $6.5 \%$ increase in sharing information about walking away and a $5.6 \%$ increase in shared information about shaking dangers among those who received the PURPLE materials compared with those who received the control materials. Reading or viewing the materials, or both, was associated with higher scores for crying knowledge. In contrast with our study, the Seattle study found that there was a significant 1.3 point increase in shaking knowledge but that there was no difference in sharing knowledge about crying and walking away from inconsolable crying. There were no site-specific differences related to where or when the materials were received. This suggests that there might be a small benefit of early interventions after birth or by public health nurses.

\section{Limitations}

Our study had a number of limitations. First, although men are the most common perpetrators of shaking, ${ }^{42-44,46}$ we studied changes for mothers only. We considered mothers to be most important because they are most likely to be reached by intervention programs and are primary caregivers. As such, they need to know about the normality of crying, the frustration it produces and the dangers of shaking. We also considered mothers to likely be the best educators of other caregivers ${ }^{5}$ and to be more likely to choose appropriate caregivers. ${ }^{6}$ Mothers are the second or third most common perpetrators of shaking. ${ }^{42-44,46}$

The second limitation of our study was that the outcome measures were based on maternal reports, not direct observations. Entries in Baby's Day Diary have the advantage of being less susceptible to memory bias, but only 4 days of behaviour were sampled. Third, missing data may have resulted in biased estimates unless the data were missing at random. Fourth, we did not adjust for multiple outcomes, which increases the probability of findings based on chance. Finally, these results may not be generalizable to other populations. However, our trial was moderately large, had a blinded, randomized controlled design, and we performed intention-totreat analyses with known data. It is less likely that missing data biased the findings because we performed parallel sensitivity analyses using multiple imputation methods.

\section{Conclusions}

This study was not designed, nor was it large enough, to test whether receipt of the PURPLE materials reduced the incidence of shaken baby syndrome. However, these results are encouraging that some knowledge and behaviours may be amenable to change when materials are delivered soon after birth during home visits by public health nurses. These findings complement the small number of reports ${ }^{4,32}$ that have reported that practical and contextually relevant materials presented to parents before or shortly after birth can change knowledge and behaviours and perhaps reduce the incidence of shaken baby syndrome. ${ }^{4}$ Whether the materials from the Period of PURPLE Crying program reduce the incidence of shaken baby syndrome and other forms of inflicted trauma to infants when implemented in clinical practice and community settings remains to be examined.

This article has been peer reviewed.

Competing interests: Marilyn Barr is the executive director of the National Center on Shaken Baby Syndrome (NCSBS), a nonprofit organization. She receives no support other than salary support as executive director of NCSBS. Ronald Barr is a member of the International Advisory Board of NCSBS. He receives no compensation for this role other than travel and lodging expenses for meetings. Ronald Barr and Marilyn Barr are married. Ronald Barr and NCSBS jointly hold the registered trademark for The Period of PURPLE Crying (Reg. No. 2,962,262). Ronald Barr received no financial benefit from Period of PURPLE Crying products sold by NCSBS through to the end of June 2007. In December 2007, the governing board of the NCSBS offered a royalty agreement to Ronald Barr for a minor share of the net profits from the future sale of Period of PURPLE Crying products in recognition of his intellectual property contribution. Marilyn Barr was not involved in the creation of this agreement. She was intentionally excluded and uninvolved in the discussions, preparations and review of the agreement to avoid any perception of a conflict of interest. The agreement was signed on December 22, 2007.

Rollin Brant is a biostatistical consultant to CMAJ and was not involved in the editorial decision-making process for this article.

None declared for Takeo Fujiwara, Jocelyn Conway and Nicole Catherine.

Contributors: Ronald Barr and Marilyn Barr were responsible for the conception and design of the study. Ronald Barr, Marilyn Barr, Jocelyn Conway and Nicole Catherine were responsible for the acquisition of data. Takeo Fujiwara, Rollin Brant and Ronald Barr performed the data analysis and interpretation. Ronald Barr drafted the manuscript, and all of the authors revised it critically for important intellectual content. Ronald Barr and Marilyn Barr obtained the funding for this study, and supervised this study along with Nicole Catherine and Jocelyn Conway. All of the authors approved the version submitted for publication.

Acknowledgements: The authors acknowledge the collaboration of the following individuals: Jessica Lam, Cynthia Lee, Brianne Grant, Claire Yambao and Yuki Li (Centre for Community Child Health Research, Vancouver, BC); Barbara Selwood, RN (BC Children's and Women's Hospital); managers, educators and nurses at BC Women's and Lions Gate Hospitals and at the Three Bridges, North, Evergreen, Pacific Spirit, Raven Song, Parkgate, Central and West Health Units (Vancouver Coastal Health Authority); managers, educators and nurses at Burnaby, Langley Memorial, Surrey Memorial and Royal Columbian Hospitals and at the Burnaby, Cloverdale, Guildford, Langley, Newton, North Surrey, North and South Delta, New Westminster, Port Coquitlam and Tri-Cities Health Units (Fraser Health Authority); Dr. Jennifer $\mathrm{McNab}$, director (Telephone Survey Unit, Department of Epidemiology and Biostatistics, University of Western Ontario, London, Ont.); and Clara Robbins and Jeremy Berland (BC Ministry of Children and Family Development).

Funding: This study was supported by the British Columbia Ministry of Children and Family Development, the British Columbia Children's Hospital, the Human Early Learning Partnership, and a Child and Family Research Institute establishment grant to Ronald Barr. None of the funding agencies had any role in the design and conduct of the study; the collection, management, analysis and interpretation of the data; or the preparation, review or approval of the manuscript. 


\section{REFERENCES}

1. Barlow KM, Minns RA. Annual incidence of shaken impact syndrome in young children. Lancet 2000;356:1571-2.

2. Keenan HT, Runyan DK, Marshall SW, et al. A population-based study of inflicted traumatic brain injury in young children. JAMA 2003;290:621-6.

3. Klevens J. Prevention of inflicted neurotrauma: what we know, what we don't know, and what we need to know. In: Reece RM, Nicholson CE, editors. Inflicted childhood neurotrauma. Elk Grove Village (IL): American Academy of Pediatrics; 2003: p. 269-79.

4. Dias MS, Smith K, deGuehery K, et al. Preventing abusive head trauma in infants and young children: a hospital-based parent education program. Pediatrics 2005; 115:e470-7.

5. Barr RG, Trent RB, Cross J. Age-related incidence curve of hospitalized shaken baby syndrome cases: convergent evidence for crying as a trigger to shaking. Child Abuse Negl 2006;30:7-16.

6. Lee C, Barr RG, Catherine N, et al. Age-related incidence of publicly-reported shaken baby syndrome cases: Is crying a trigger for shaking? J Dev Behav Pediatr 2007;28:288-93.

7. Talvik I, Alexander RC, Talvik T. Shaken baby syndrome and a baby's cry. Acta Paediatr 2008;97:782-5.

8. Barr RG. The normal crying curve: What do we really know? Dev Med Child Neurol 1990;32:356-62.

9. Barr RG. Crying behavior and its importance for psychosocial development in children. In: Tremblay RE, Barr RG, Peters RD, editors. Encyclopedia on early childhood development. Montreal (QC): Centre of Excellence for Early Childhood Development; 2006: p. 1-10.

10. Barr RG. Excessive crying. In: Sameroff AJ, Lewis M, Miller SM, editors. Handbook of developmental psychopathology. 2nd. ed. New York (NY): Kluwer Academic/ Plenum Press; 2000: p. 327-50.

11. St. James-Roberts I, Alvarez M, Csipke E, et al. Infant crying and sleeping in London, Copenhagen and when parents adopt a 'proximal' form of care. Pediatrics 2006;117:e1146-55.

12. Barr RG, Paterson J, MacMartin L, et al. Prolonged and inconsolable crying bouts in infants with and without colic. J Dev Behav Pediatr 2005;26:14-23.

13. Committee on Child Abuse and Neglect of the American Academy of Pediatrics Shaken baby syndrome: rotational cranial injuries: technical report. Pediatrics 2001;108:206-10

14. Canadian Association of Chiefs of Police, Canadian Institute of Child Health, Canadian Paediatric Society, Canadian Public Health Association, Child Welfare League of Canada, Health Canada, Saskatchewan Institute on Prevention of Handicaps, The Canadian Bar Association. Joint statement on shaken baby syndrome. Paediatr Child Health 2001;6:663-7.

15. Barr RG; National Center on Shaken Baby Syndrome. Period of PURPLE crying. Ogden (UT): National Center on Shaken Baby Syndrome; 2004.

16. Barr RG. Baby's day diary. Montréal (QC); 1985 [available from the author].

17. Soltis J. The signal functions of early infant crying. Behav Brain Sci 2004;27:443-58.

18. Canadian Pediatric Society. Safety tips for parents. The Society; 2002.

19. Health Canada, Canadian Pediatrics Society, Canadian Institute of Child Health, The Canadian Foundation for the Study of Sudden Infant Deaths. Back to sleep. Ottawa (ON): Health Canada; 1999

20. National Institute of Child Health and Human Development. Back to sleep sudden infant death syndrome: A video on helping to reduce the risk. Bethesda (MD): The Institute, Medical Arts and Photography Branch, NCRR National Institute of Health; 1999.

21. Safe Start. Child safety: Learn how to keep your child safe and injury free. Vancouver (BC): Force4 Productions Ltd.; 1992.

22. Barr RG, Kramer MS, Leduc DG, et al. Parental diary of infant cry and fuss behaviour. Arch Dis Child 1988;63:380-7.

23. Hunziker UA, Barr RG. Increased carrying reduces infant crying: a randomized controlled trial. Pediatrics 1986;77:641-8.
24. Barr RG, Kramer MS, Pless IB, et al. Feeding and temperament as determinants of early infant cry/fuss behaviour. Pediatrics 1989;84:514-21.

25. St. James-Roberts I, Hurry J, Bowyer J. Objective confirmation of crying durations in infants referred for excessive crying. Arch Dis Child 1993;68:82-4.

26. Calinoiu N, Barr RG, Lehtonen L, et al. Diary indices of pacifier use: convergence with interview measures. Vancouver (BC): International Society of Infant Studies; 1998.

27. Majnemer A, Barr RG. Association between sleep position and early motor development. J Pediatr 2006;149:623-9.

28. Barr RG, Calinoiu N. RonNicLog baby's day diary counting program. Montréal (QC); 1997 [available from the author]

29. Lehtonen L, Barr RG, Calinoiu N, et al. Pacifier use in infants with and without colic: Is it really effective? Vancouver (BC): International Society of Infant Studies; 1998 .

30. Kramer MS, Barr RG, Dagenais S, et al. Pacifier use, early weaning, and cry/fuss behavior. A randomized controlled trial. JAMA 2001;286:322-6.

31. Kramer MS, Feinstein AR. Clinical biostatistics LIV. The biostatistics of concordance. Clin Pharmacol Ther 1981;29:111-23.

32. Barr RG, Rivara FP, Barr M, et al. Effectiveness of educational materials designed to change knowledge and behaviors regarding crying and shaken baby syndrome in mothers of newborns: a randomized controlled trial. Pediatrics. In press.

33. Royston P. Multiple imputation of missing values: update of ice. Stata J 2005; 5:527-36.

34. Little RJA, Rubin DB. Statistical analysis with missing data. Hoboken (NJ): John Wiley and Sons; 2002

35. Glynn RJ, Buring JE. Ways of measuring rates of recurrent events. BMJ 1996;312:364-7.

36. Cummings $\mathrm{P}$, Norton R, Koepsell TD. Rates, rate denominators, and rate comparisons. In: Rivara FP, Cummings P, Koepsell TD, et al. editors. Injury control: a guide to research and program evaluation. New York (NY): Cambridge University Press; 2001. p. 64-74

37. Brookes ST, Whitely E, Egger M, et al. Subgroup analyses in randomized trials: risks of subgroup-specific analyses; power and sample size for the interaction test. J Clin Epidemiol 2004;57:229-36.

38. Catherine N, Ko JJ, Barr RG. Getting the word out: advice on crying and colic in popular parenting magazines. J Dev Behav Pediatr 2008;29:508-11

39. Dias MS. Program reminds new parents of dangers of violent shaking. AAP News 2003 July. p. 16.

40. Cohen J. A power primer. Psychol Bull 1992;112:155-9.

41. Layzer JI, Goodson BD, Bernstein L, et al. National evaluation of family support programs. Final report volume A: the meta-analysis. Cambridge (MA): Abt Associates Inc; 2001. p. A5.1-A5.37.

42. Lazoritz S, Baldwin S. The whiplash shaken infant syndrome: Has Caffey's Syndrome changed or have we changed his syndrome? Child Abuse Negl 1997;21:1009-14.

43. Starling SP, Holden JR, Jenny C. Abusive head trauma: the relationship of perpetrators to their victims. Pediatrics 1995;95:259-62.

44. Starling SP, Patel S, Burke BL, et al. Analysis of perpetrator admissions to inflicted traumatic brain injury in children. Arch Pediatr Adolesc Med 2004;158:454-8.

45. Willinger M, Hoffman HJ, Hartford RB. Infant sleep position and risk for suddent infant death syndrome: report of meeting held January 13 and 14, 1994, National Institutes of Health, Bethesda, MD. Pediatrics 1994;93:814-9.

46. Brewster AL, Nelson JP, Hymel KP, et al. Victim, perpetrator, family, and incident characteristics of 32 infant maltreatment deaths in the United States Air Force. Child Abuse Negl 1998;22:91-101.

Correspondence to: Dr. Ronald G. Barr, Centre for Community Child Health Research, 4480 Oak St., L408, Vancouver BC V6H 3V4; fax604 875-3589; rbarr@cw.bc.ca 